\title{
Research on the Optimization Model of Postgraduate Joint Training in Graduate Workstation in New Perspective
}

\author{
Lin Li \\ Department of Mechanical Engineering, North China Electric Power University, Baoding, China
}

Izx615@126.com

Keywords: Graduate Workstation, Joint Training, optimization model

\begin{abstract}
The joint training mode in the graduate workstation is for high-level applied talents, which has been paying more and more attention by the education sector. In the process of cultivating postgraduate, this training mode can give full play to the advantages of the parties and enhance practical ability and creativity of graduate students. Aiming at the deficiencies in the implementation and construction of the present graduate workstation, this paper analyzes the joint training mode of the postgraduates in the workstation. This paper studies the mechanism and measures of university and enterprise cooperative training, designs and optimizes the training programs and training links, which can provide theoretical help for further enhancing the important role of graduate workstation in personnel training, regional innovation and service.
\end{abstract}

\section{Introduction}

Graduate education is the main way to cultivate high-level talents and an important part of the national innovation system. The postgraduate training mode and quality is an important indicator to measure the level of graduate education. In recent years, with the constant expansion of graduate enrollment and shortening of educational system, there is an increasing demand for the training mode and the quality of postgraduate. How to cultivate innovative, compound and practical talents has been a popular topic of national education [1]. Graduate workstation can accelerate the construction of regional innovation system and it is an important measure in the implementation of innovation driven strategy and an important carrier to enhance the independent innovation capability of enterprises. It is also an important channel for postgraduate training units to serve local economic and social development and an important way to improve the quality of graduate education to cultivate high-level innovative talents. As a new industry-university-research cooperation and personnel training mode, at the beginning of the site, the enterprise graduate workstation has a clear direction of $R \& D$ and personnel training. There are special mentors and special joint research and training venues and facilities in the workstation. The graduate workstation has a depth cooperation with the industry-university-research and brings a new situation for cooperative innovation and collaborative training [2-6]. It is of great significance to study the optimal operation mode of postgraduate joint training under the new visual field in order to ensure the rapid development of graduate workstation.

\section{Problems in Joint Training in Workstation Mode}

Graduate workstation is generally arranged after the learning of theoretical courses in school, which is for the postgraduate go to the enterprise to participate in scientific research projects, namely called "school + enterprise" model [7-9]. However, from the view of a systematicness and process, of personnel training, the new graduate training mode in enterprise graduate workstation covers two stages of school and enterprise. But, at present, there is a lack of organic connection and interaction between the two stages, mainly reflected in:

(1)The engagement of enterprise in designing and formulating the postgraduate's training programs and curriculum is not enough and the particularity of postgraduates in the graduate workstation is not been considered fully, which would keep the workstation doing its job well; currently, the graduate students are generally limited to participate the project development, 
preliminary studies and research and daily work, and the relevant training that is proposed by the Department of education don't carry out barely and it is difficult to find the combination point. The postgraduates needs take long time to be familiar with the project background knowledge, learn the enterprise system and standardize and supply the relevant theoretical knowledge. This would reduce the efficiency of scientific research and the waste of valuable time in graduate workstation.

(2)The enterprise mentor is not familiar with the process and standard about the training of graduate students. So, there are many problems in the process of tutor's guidance. The enterprise can't put forward the reasonable and systematic research task and often solve the problems by experience. Because of the thinking habits, work methods, theoretical foundation and other reasons, enterprise mentors are not good at communication with the graduate students, which reduces the phenomenon of bad guidance. Taking the graduate project of postgraduates in the Jiaxun photoelectricity workstation as an example, a study for the photovoltaic power plant components array loss is called "smart junction box" requires graduate to design and debug just with putting forward some rough index. The constant modifying the e parameters and functional requirements make a major change in the selection of principle design and components, which leads to take 3 months to complete the first sample test and the delay graduation of the postgraduates in the workstation.

(3)The funds that the enterprises input into the graduate workstations is imbalance. Some enterprises attach great importance to the talent strategy, and regard taking part in the personnel training as a responsibility of their own. Thus, the funds in those graduate workstations is sufficient,. For example, Jiaxun photoelectricity Industry in Changzhou inputs more than 5 million yuan into the project where the graduates take part in recently and the projects which is finished by the postgraduates independently have amounted to 100 thousand yuan. But, some enterprises even can't afford the 600 yuan graduate living subsidies monthly which is written in the agreement. Part of the burden is passed on to the school, resulting in the implementation of compressed part of the project. In the development of the project, the graduate and the tutor proposed that the project plan outside the enterprise is difficult to implement because of insufficient funds.

\section{Research on Optimization Model of Postgraduate Joint Training in Workstation}

Smoothly carrying out the graduate students' joint training work in workstations not only can both ensure that graduate students effectively improve their comprehensive quality and exercise their practical operation ability, but also can inject new vitality into enterprise for scientific research innovation. Whether the joint training mode of graduate students in workstation mode is good or not will directly affect the effect of workstation construction. Aiming at the practical problems in the process of carrying out graduate workstation, the realization of the optimal mode of joint training for graduate workstation needs to make the following efforts:

To Carry Out Education Work to Meet the Personality Needs of Graduate Students. Combined with graduate training program, to further clarify the responsibilities of college tutors and corporate tutors in the process of postgraduate training, establish a mechanism of cooperation, interaction and exchange, strengthen the duties of double tutors. According to the needs of enterprises, the colleges and universities should select the teachers with strong sense of service consciousness and responsibility, rich experience in technology research and development as the graduate guidance teacher for the postgraduates in workstations; the enterprises should employ the engineering technology backbone with high professional and technical capacity as the postgraduate tutors. In the interaction, college teacher should help the enterprise teacher to have the theory courses, compile textbooks and handouts, promote the update of teaching material, and help enterprises to cultivate academic norms, familiar with the tutor system and the process of high graduate tutor. The enterprise tutor should give students specific guidance in the background knowledge, relevant experimental technical difficulties of postgraduates' subjects. The enterprise tutor should also guide the student in the practice and regularly communicate with the college teacher to help the college graduate tutor understand the postgraduates' performance in workstation. The implementation of double tutor system can guarantee the real-time guidance of student research 
work, which can meet the individual needs of students and achieve the purpose of improving the level of postgraduate training.

Developing Open Workstation Task Research System. Establishing key subject research system in enterprise. The enterprises set up open subject system can base on the provincial and ministerial level scientific research projects or rely on the ongoing research and development tasks. The enterprise should have scientific planning with open topic selected with cutting-edge academic, practical practice, systematic theory. According to the postgraduate training mode and training target, more perfect topic selection mechanism should be established to concise out the topic which is in line with the objectives of the graduate training project, the subjects and the project management should be standardized for the implementation of graduate workstation with scientific research projects as the guide of the target. Although the topic of graduate student is very extensive, but only selecting research that is advanced, practical and systematic, according to the problems which are urgent, heavy, difficult and new in the enterprise, can more will present the research content and the actual production together. This not only can ensure to cultivate the ability of scientific research and innovation of postgraduates, but also ensure that the research results can be better applied to actual production.

Perfecting the Internal System Construction of Graduate Workstation. After the enterprise graduate workstation entering the application state through advance investment and preparations, the specific system and method must be established to ensure the operation management of the workstation.

Setting up Enterprise Graduate Workstation Management Agency. Station enterprise is the main body of the construction and management of graduate workstation, and the enterprises should take the establishment of enterprise graduate workstation management, enterprise and university cooperation plan and implementation plan, the implementation of research funding, the selection of graduate students, ensure the scientific research and living conditions of graduate students and instructors and provide living allowance for the doctoral and master students in the workstation.

Formulating and Implementing Reasonable Enterprise Graduate Workstation Management Approach. To effectively manage the graduate workstation, it is necessary to develop reasonable management practices and implement them. It is necessary to draft the selection methods, personnel management methods, fund management measures, scientific research results management measures, and living support measures for enterprise graduate workstation on the basis of full investigation. The drafting of the enterprise graduate workstation management approach is on the basis of expert discussion approved by the management committee. Once approved, strictly enforced.

Implementing Project Periodic Assessment System. Under the premise of the normal management of the enterprise graduate workstation, it is necessary to strengthen the examination of the enterprise graduate workstation. With the scientific research topic as the link, the enterprise tutor, the school tutor and the transfer graduate student are linked. The project responsibility should be strengthen to realize the graduate union training goal with the project management.

Carrying out the Incentive Graduate Work, Maintaining the Interests of Graduate Students as the Fundamental. The enterprise should establish the incentive mechanism for the workstation. Different enterprise senior technical personnel should be regularly organized to have the operation training of production theory for postgraduates. The enterprise also organize the postgraduates to visit and study in different part of the enterprise, regularly held various forms of academic exchange, regularly report and grade the performance during the training and implement the corresponding evaluation incentive mechanism. The workstation should establish the excellent graduate enterprise retention mechanism. For the outstanding graduate in the enterprise to be retained, the graduate employment contract signed. The mechanism not only protects the rights and interests of graduate students, but also enables enterprises to discover talents and choose talents as early as possible.

Presetting Special Funds, Increasing Investment and Creating a Good Platform for Joint Training. Joint training needs the graduate workstation platform, and establishing the enterprise 
graduate workstation must have a good environment for scientific research, for example, having a certain scale of production, urgent requirements for technological innovation and clear direction of product development, the hardware facilities like a key laboratory, and having special funds to ensure postgraduate workstation running. Only have certain hardware and software facilities, enterprise graduate workstation operates normally. In the process of establishment and implement of graduate workstation, there were some enterprises don't set up special funds after the establishment, thereby affecting the normal operation of workstation, which making the joint training becomes empty talk. So there must be special funds in the enterprise graduate workstation management in advance, or there must be sources or the use of funds in the management approach and contract agreed.

\section{Conclusion}

With the development of social economy, the increasing demand for high-level talents raises new and higher requirements for the cultivation mode of graduate students. The joint cultivation of graduate students in the workstation mode can further improve the quality of graduate education, so as to cultivate application-oriented, complex, and highly qualified talents. Aiming at some practical problems existing in the joint training of workstation postgraduates, this paper studied the optimal operation mode, and put forward some suggestions. The author expects these practices and recommendations can be more effectively used in the process of graduate workstation training, so as to keep the workstation to work more orderly and smoothly, and then meet the needs of enterprise research and development.

\section{Acknowledgements}

This research is supported by the Fundamental Research Funds for the Central Universities (2016MS113)

\section{Reference}

[1] $\mathrm{Wu}$ Qun, Xu Yan. Reform and innovation of training mode of enterprise postgraduate workstation [J]. China Education of Light Industry, 2011(6):6-7.

[2] Ao Yongsheng. Enterprise graduate workstation training full-time professional degree graduate students to explore [J]. Degree and graduate education, 2011(3):68-72.

[3] Zhang Xiang. Research on quality assurance mechanism of enterprise postgraduate workstation personnel training [J]. Chinese off campus education, ,2012(6):54-55.

[4] Luo Wenwei, Zhang Honghai. Establishment of graduate workstation in local colleges and Universities under synergetic innovation thought [J]. modern education, 2013 (13-14): 20-22.

[5] Shen Jinrong, Lei Kai. Problems and Countermeasures of graduate workstation in Chinese enterprises [J]. Journal of Nanjing University of Science and Technology (SOCIAL SCIENCE EDITION), 2011,24 (5): 92-96.

[6] Jiang Wenchun, Liu Renhuan, Wang Zhenbo. Some thoughts on the construction of graduate workstation and student training [J]. China modern education equipment, 2012 (20): 13-15.

[7] Wang Bochao, Lu Hui, Yin Chengqun school and enterprise to build graduate workstation exploration and practice of innovative talents: a case study of North China Electric Power University [J]. China Electric Power Education, 2012 (6): 54-55.

[8] Shen Jinrong, Lei Kai, Shi Long Cang. Research on practice and mechanism of graduate engineering practice education platform [J]. higher engineering education research, 2011 (6): 
131-135.

[9] Wang Li, Guo Gengyu. Cultivation and practice of professional degree postgraduate based on "station school model" [J]. China Vocational and technical education, 2013 (36): 76-79. 